$$
\begin{aligned}
& \text { تأثير المسافة بين المبازل على ارتفاع الماء الارضي وملوحة التربة } \\
& \text { انتصار محمد غزال / استاذ مساعد إدما } \\
& \text { قسم الموارد المائية/ كلية الهندسة/ جامعة الموصل }
\end{aligned}
$$

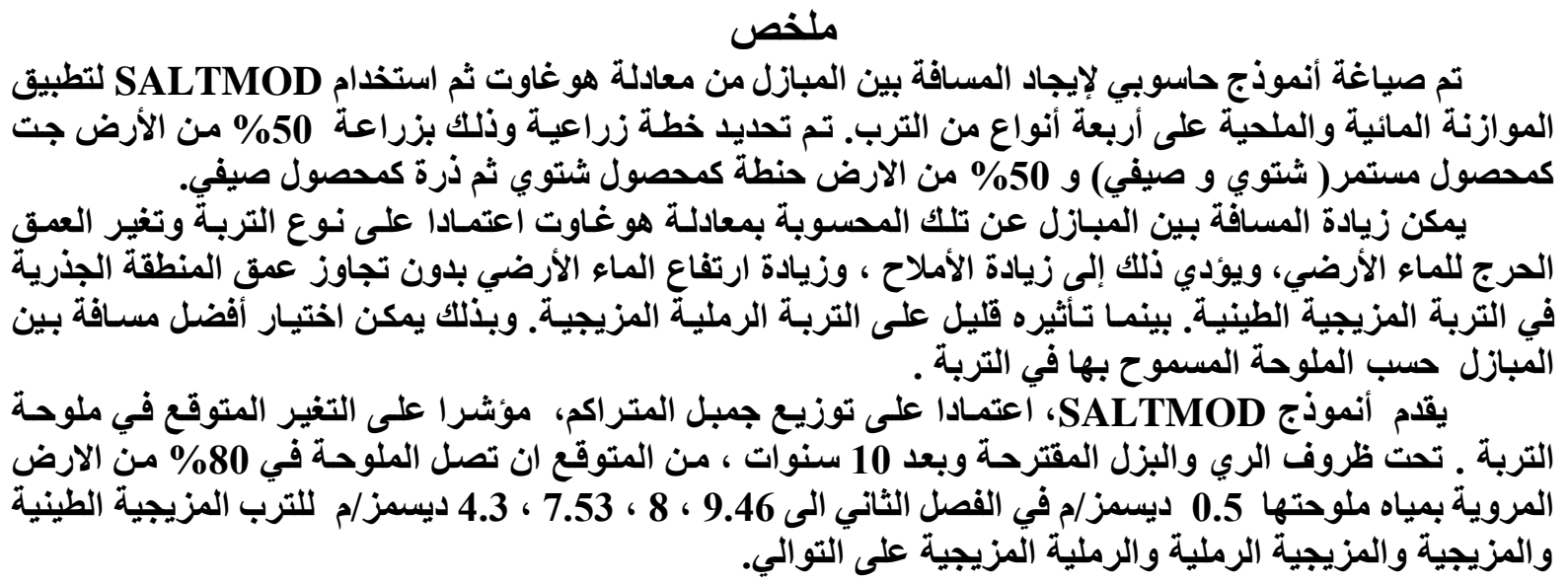

\title{
Effect of Drain Spacing on Water Table Depth and Soil Salinity
}

\author{
Entesar M.Ghazal \\ Water resources Engineering Department \\ College of Engineering / University of Mosul
}

\begin{abstract}
A computer model was made to find drain spacing with Hooghout equation then SALTMOD was applied for water and salt balances of four different soils. Crop rotation with alfalfa in $50 \%$ of the land as continuous crop(in winter and summer) and $50 \%$ of the land wheat in winter then maize in summer season.

Drain spacing can be increased than that calculated with Hooghout equation according to soil type and critical water table depth, So salinity, and water table depth were increased without exceeding root zone depth, in clay loam soil. Whereas it's increase has little effect on loamy sand soil, therefore, the best drain spacing can be chosen according to acceptable salinity in the soil .

SALTMOD gives, depending on cumulative Gumbel distribution, a reasonable indication of the predicted change in soil salinity. Under the proposed conditions of irrigation and drainage after, 10 years, the root zone salinity in $80 \%$ of area irrigated with $0.5 \mathrm{ds} / \mathrm{m}$ water, was predicted to increase in summer to $, 9.46,8,7.53,4.3 \mathrm{ds} / \mathrm{m}$ in the clay loam, loam, sandy loam, loamy sand soil respectively.
\end{abstract}

Keywords :SALTMOD, root zone salinity, water table depth. 


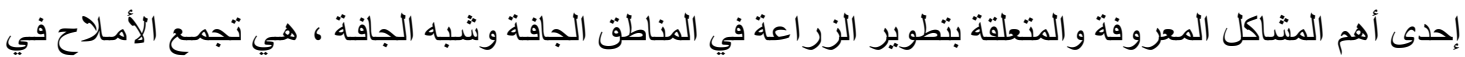

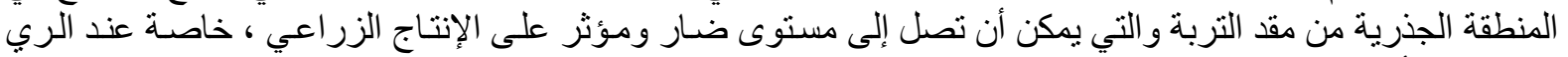
بمياه مالحة أو عدم ترشيد استخدام الماء.

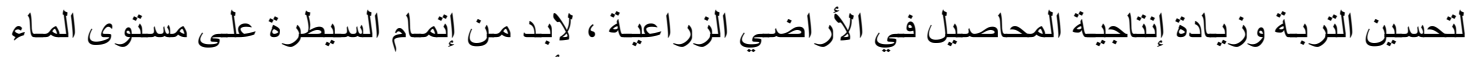

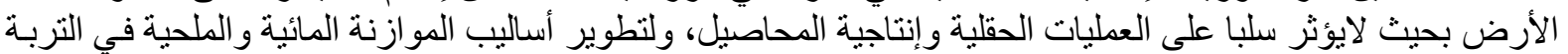

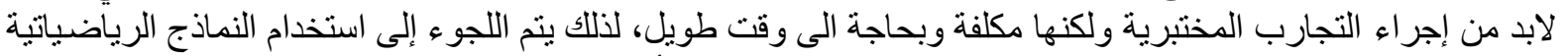

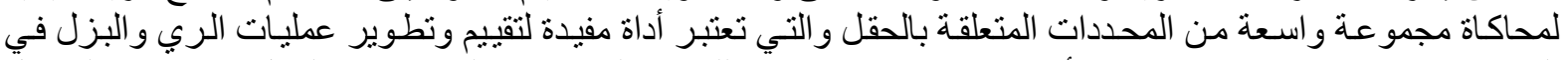

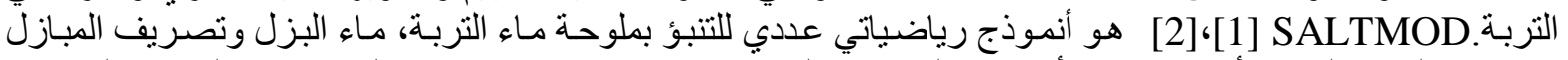

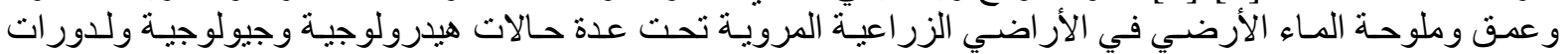

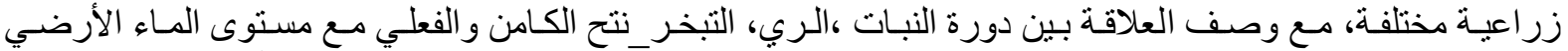

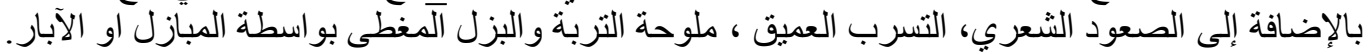

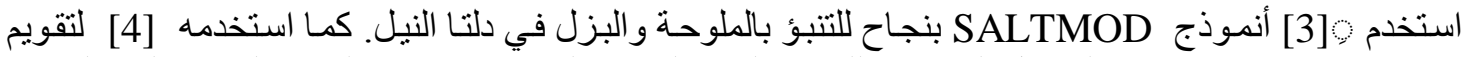

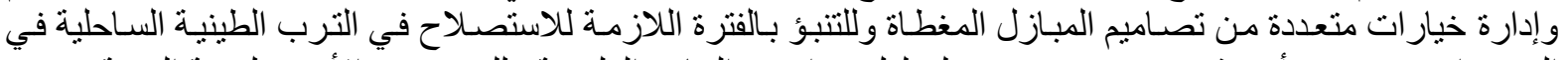

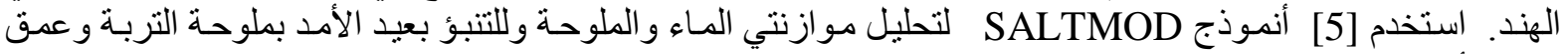
الماء الأرضي في كونانكي في النهند.

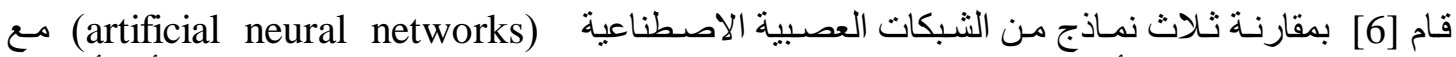

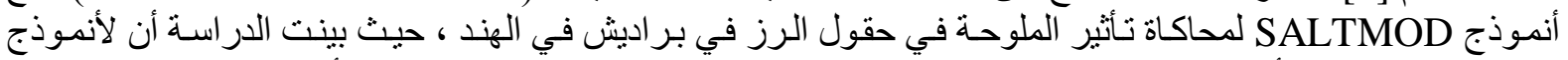
SALTMOD

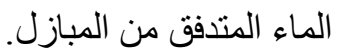

تضـنت الدراسـة التي قام بها [7] نظرة متكاملـة مـع التحسس عن بعد (remote sensing) لملوحسة التربـة

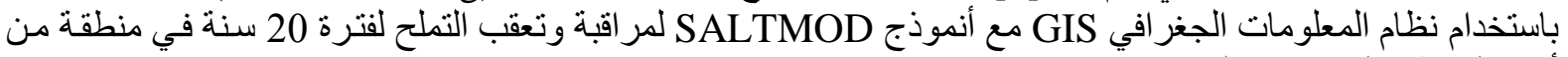
أكثر المناطق الزر اعية تملحا في تأيلاند.

قام [8] بدر اسة تأثير تغير عمق المبزل على كمية مياه البزل وملوحة المنطقة الجذرية و عمثق المـاء الأرضي في

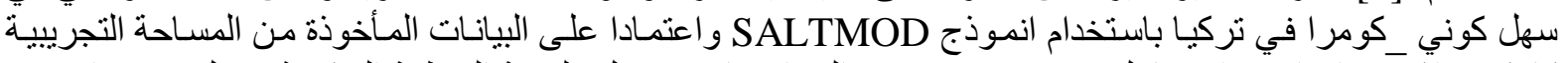

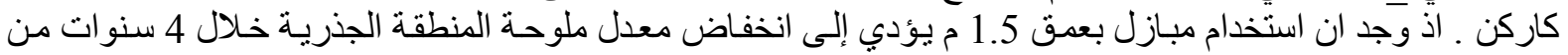

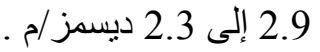

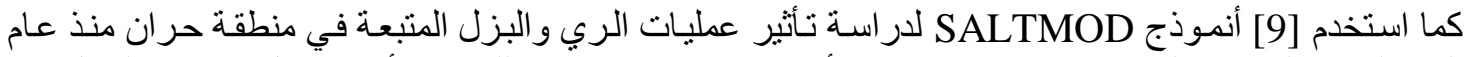

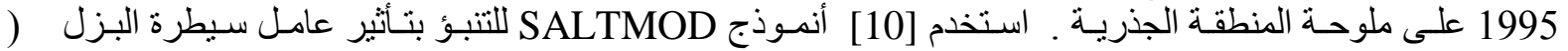
(drainage control factor

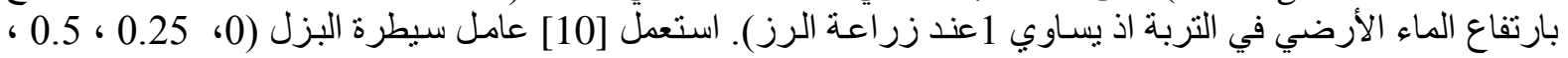

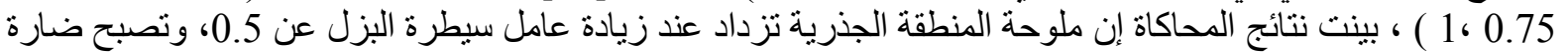

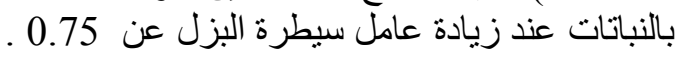

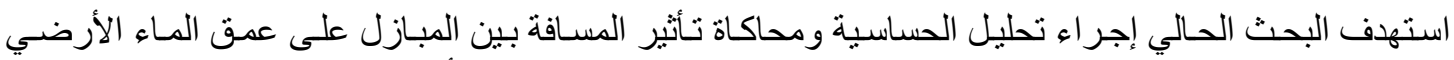

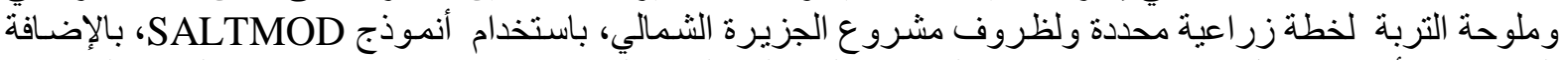
إلى در اسة تأثير استعمال مياه ري بمستويات ملوحة مختلفة على ملوحة التربة بعد 10 سنو ات من تطبيق الخطة الزر اعية بالافية

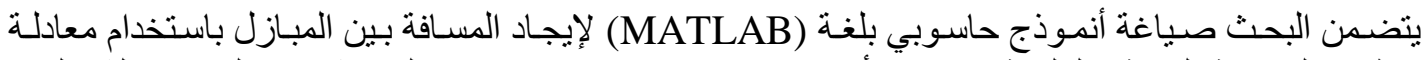

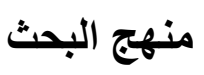

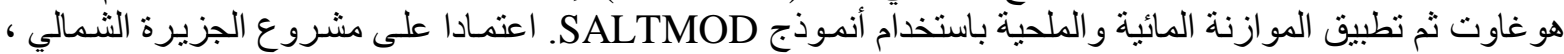

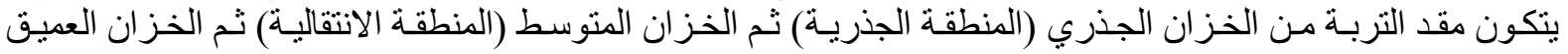




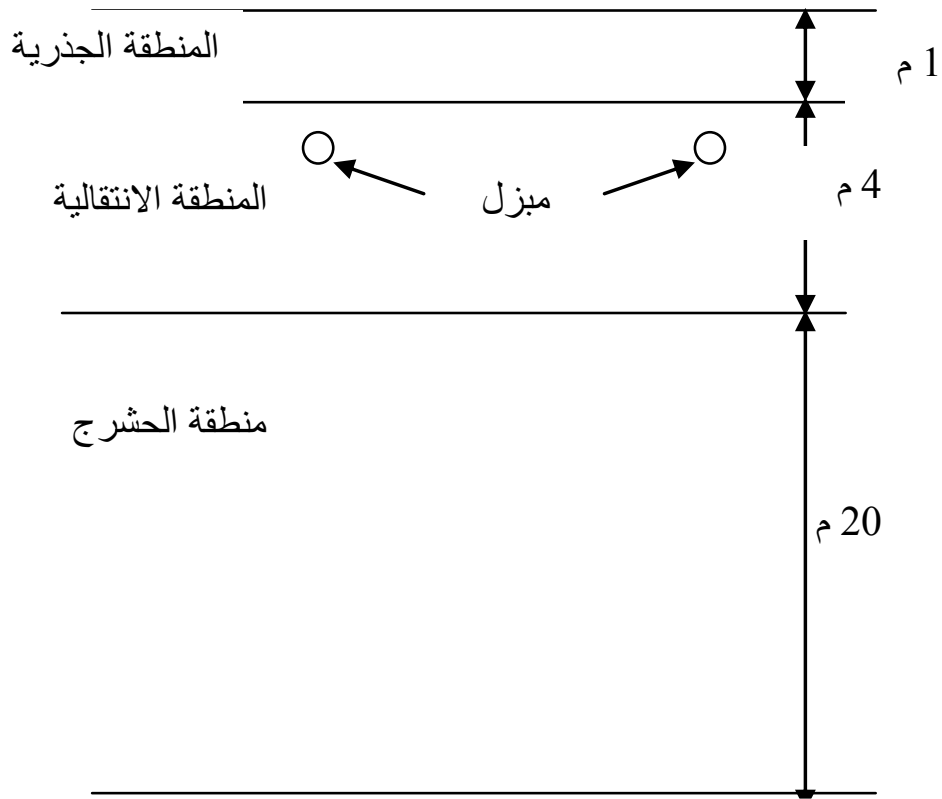

الشكل(1) رسم توضيحي لمقد التربة.

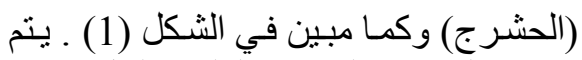

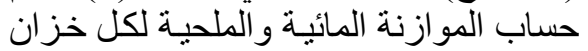
باســتخدام أنمــوذج SALTMOD

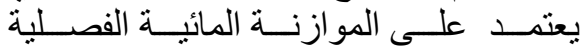

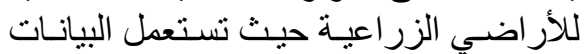
الفصلية للأمطار ، التبخر من سطح التربـة ، التربة ،

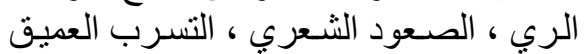

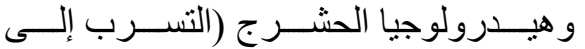

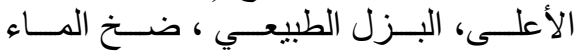

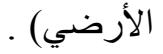

تم تحديد أربعة أنواع من الترب من

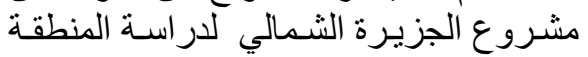

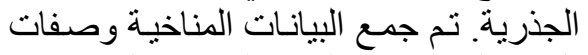

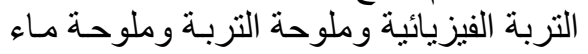

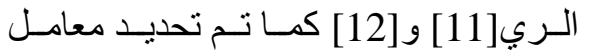

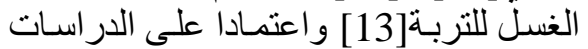

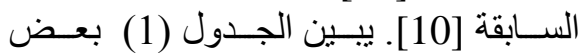

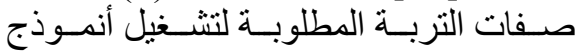
SALTMOD و هي المسامية الكلية للتربـة الكبة

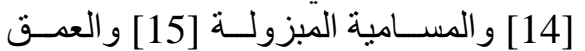

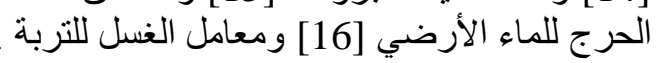

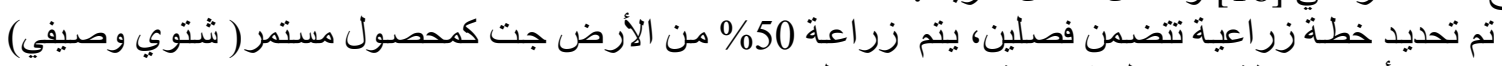
و50\% من الأرض حنطة محصول شنتوي ثم ذرة محصول صنيف نيفي.

الجدول(1) مواصفات تربة المنطقة الجذرية والانتقالية ومنطقة الحشرج.

\begin{tabular}{|c|c|c|c|c|c|}
\hline معامل & $\begin{array}{c}\text { المبزولة } \\
\text { \% }\end{array}$ & الكسامية & التهيلروليكيل & 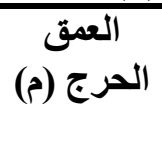 & نوع التربة \\
\hline 0.6 & 18 & 40 & 7.5 & 1.1 & رملية مزيجية \\
\hline 0.6 & 12 & 43 & 4.2 & 2.0 & مزيجية رملية \\
\hline 0.5 & 9 & 47 & 1.8 & 1.5 & مزيجية \\
\hline 0.4 & 6 & 50 & 1.0 & 1.5 & مزيجية طينية \\
\hline 0.4 & 6 & 50 & 1.0 & - & المنطقة الانتقالية \\
\hline 0.3 & 2 & 15 & 0.3 & - & الحشر ج \\
\hline
\end{tabular}

تم حساب التبخر نتح الكامن لكل محصول بعد تحديد التبخر نتح الكامن ومعامل المحصول لكل شهر من فترة نمو التمبو

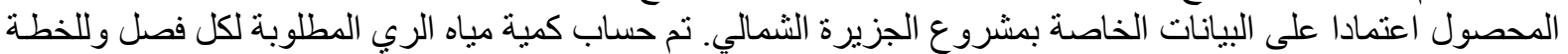

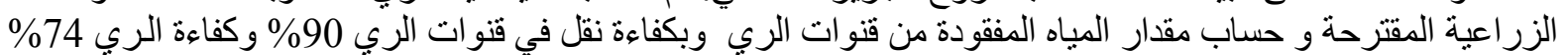

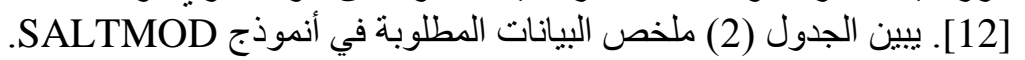

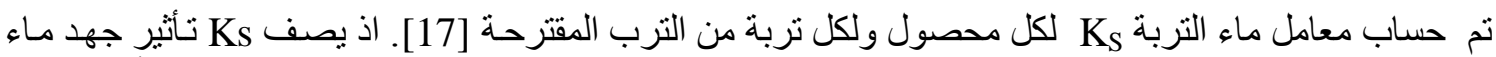

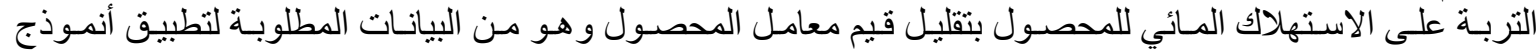

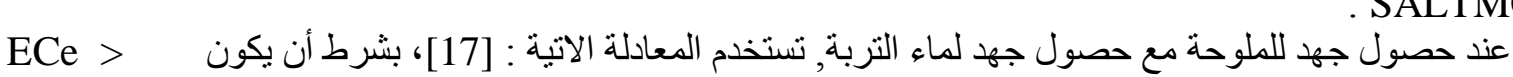
SALTMOD

Dr > RAW g ECe threshold 


$$
K s=\left(1-\frac{b}{K_{Y} 100}\left(E C e-E C e_{\text {threshold }}\right)\right)\left(\frac{T A W-D r}{(1-p) T A W}\right)
$$

الجدول(2) ملخص البيانات المطلوبة في أنموذج SALTMOD.

\begin{tabular}{|c|c|c|}
\hline الفصل الثاني & الفصل الاول & 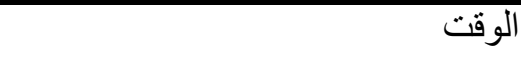 \\
\hline (من حزيران- 15/تشرين اول) & (من 15/تشرين اول - نهاية ايار) & مو عد الزر اعة \\
\hline 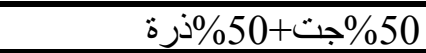 & 50\% جت+50\%حنطة & المحصول ونسبة الارض المزروعة \\
\hline 0.03 & P 0.36 & الامطار \\
\hline 1.95 & 0.835 & 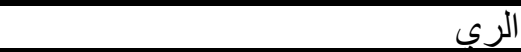 \\
\hline 0.0 & 0.0 & الماء الارضيى \\
\hline 1.97 & 1.2 & التبخر من سطح التربة \\
\hline 0.0 & 0.1 & السبح السطحى \\
\hline 0.342 & 0.146 & الفقد من قنو ات الري \\
\hline 0.11 & 0.044 & الفقد من سطح التربة \\
\hline 7 - & 7 & ملوحة المنطقة الجذرية المشبعة الأولية \\
\hline 2 & 2 & 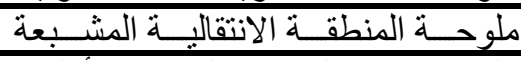 \\
\hline 3.2 ديسمز/م & 3.2 & ملوحة منطقة الحشرج المشبعة الأولية \\
\hline 2.0 & 2.0 & العمق الأولى للماء الأرضى \\
\hline
\end{tabular}

عند حصول جهد للملوحة من دون حصـول جهد لمـاء التربـة بستخدم الحد الأول فقط من المعادلة (1) على ان تكون .Dr $<\mathrm{RAW}, \mathrm{ECe}>\mathrm{ECe}_{\text {threshold }}$

p : الاستنز اف الحرج و هي النسبة المئوية من الماء المتيسر الكلي التي يستنزفها المحصول في المنطقة الجذريـة من دون

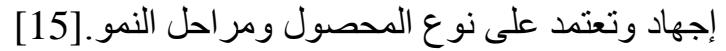
ECe : معدل التوصيل الكهربائي لمستخلص الإشباع للمنطقة الجذرية [ds/m].

ECe threshold [17].[ds/m]

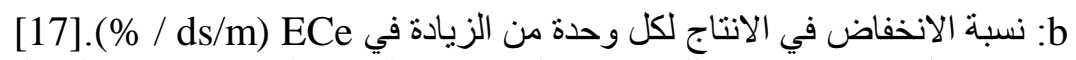

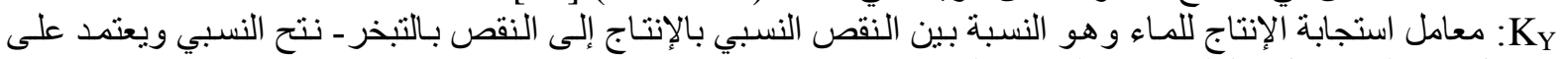

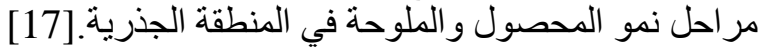
يبين الجدول (3) بعض البيانات عن المحاصيل الداخلة في الخطة الزراعية [15] ، [17] . الجدول(3 ) بيانات عن المحاصيل في الخطة الزراعية [15] و 17].

\begin{tabular}{|c|c|c|c|c|c|}
\hline $\mathbf{K}_{\mathbf{Y}}$ & $\begin{array}{c}b \\
\% / d s / m\end{array}$ & $\begin{array}{c}\text { ECe }_{\text {threshold }} \\
(\mathbf{d S} / \mathbf{m})\end{array}$ & الاستنزاف & عمق الجذر & المحصول \\
\hline 1.05 & 4.2 & 7.5 & 0.55 & 1000 & الحنطة \\
\hline 1.25 & 12 & 1.7 & 0.55 & 1000 & الذرة \\
\hline 1.1 & 7.3 & 2 & 0.55 & 1000 & الجت \\
\hline
\end{tabular}

يعبر عن ملوحة التربة في انموذج SALTMOD بمعدل التوصيل الكهربائي للتربة المشبعة في الحقل EC و التي 


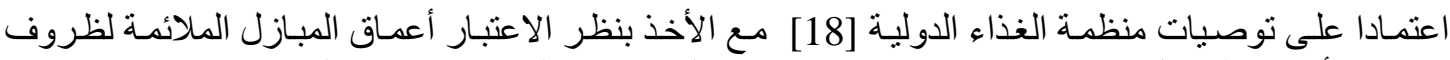

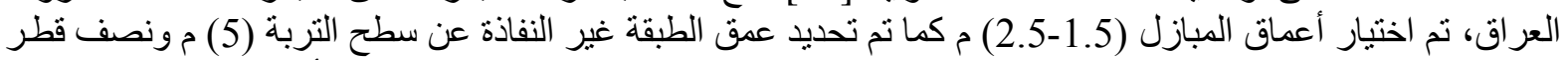

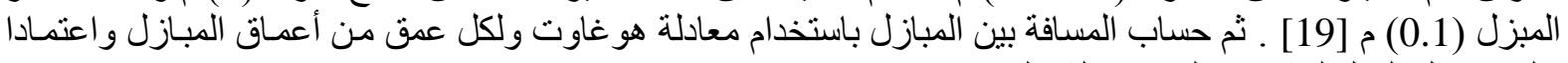

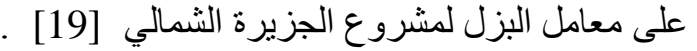

$$
\begin{aligned}
& r=\frac{8 K_{2} d h}{L^{2}}+\frac{4 K_{1} h^{2}}{L^{2}} \\
& d=\frac{D}{1+\left[\frac{8 * D}{\pi * L} \ln \frac{D}{u}\right]}
\end{aligned}
$$$$
\text { يمكن حساب العمق المكافئ لهوكاوت من المعادلة الآتية: }
$$$$
h=d d-p w d
$$

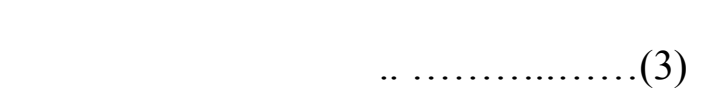

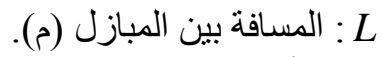

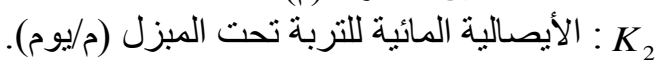

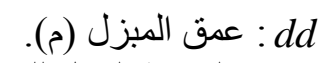

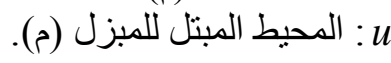

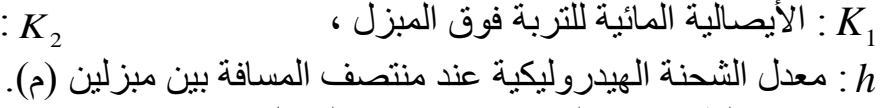

r: r معامل البزل = 0.003 (م/يوم).

إذ أن: h

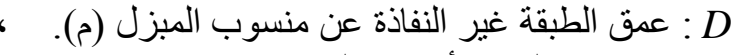

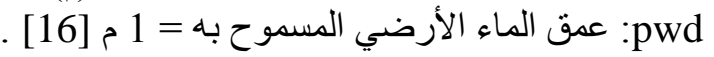

يعبر عن المسافة بين المبازل في أنموذج

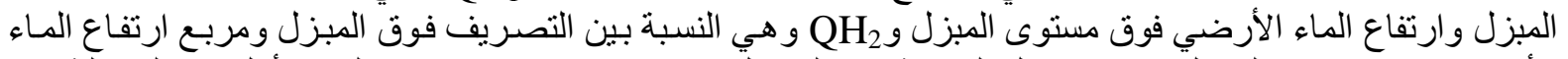

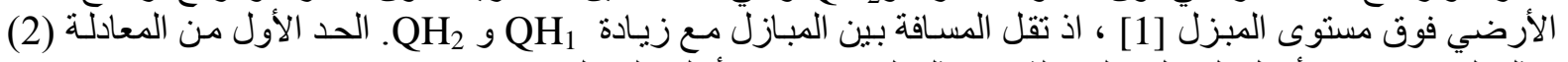

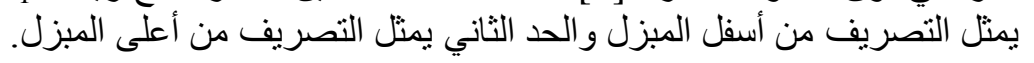

$Q H_{1}=\frac{8 K_{2} d h}{L^{2} h}$

$Q H_{2}=\frac{4 K_{1} h^{2}}{L_{2} h^{2}}$

لإجر اء تحليل الحساسية ولمحاكاة تأثثر المسافة بين المبازل على ملوحة التربـة ، تم حسـاب قيم

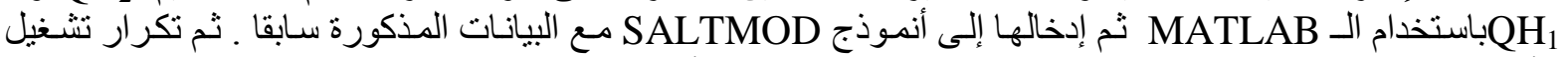

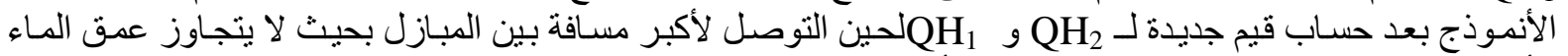

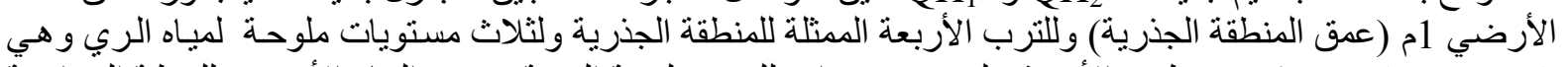

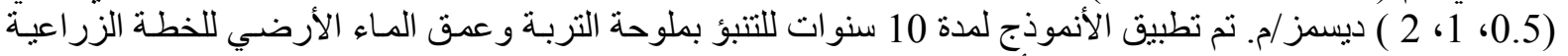

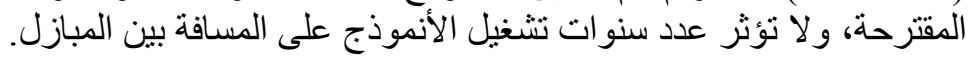

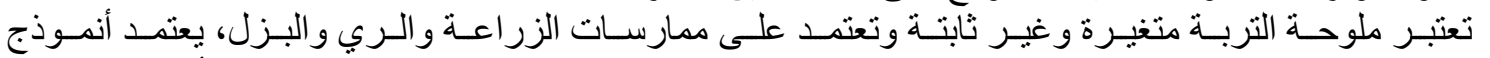
SALTMOD

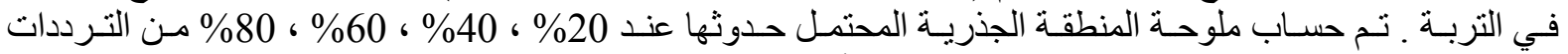
المتر اكمة(cumulative frequencies) وبذللك يقدم أنموذج SALTMOD مؤشرا على التغير المنوقع في ملوحة ، 


\section{النتائج و المناقشة}

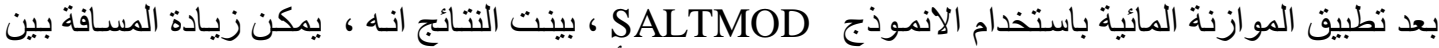

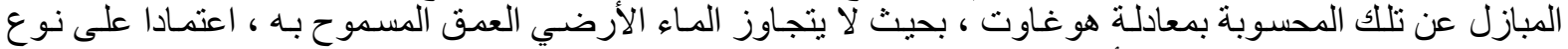

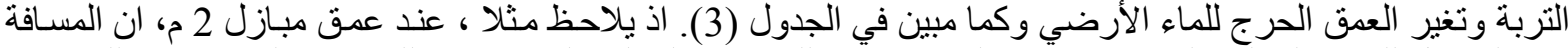

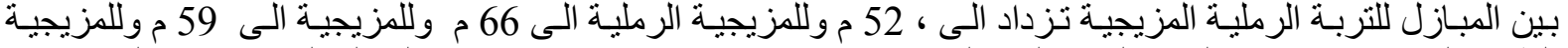

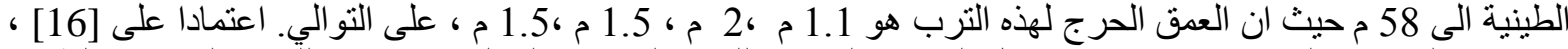

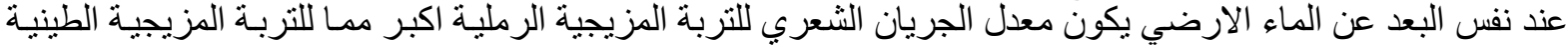

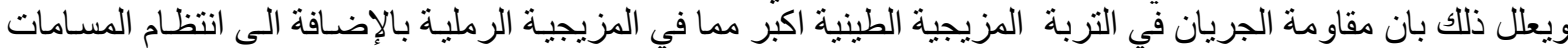

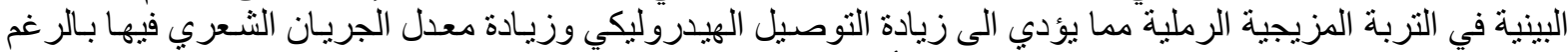

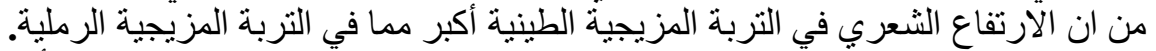

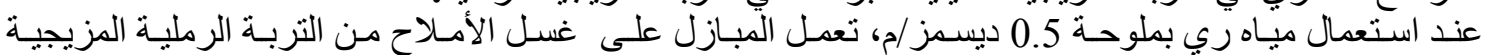

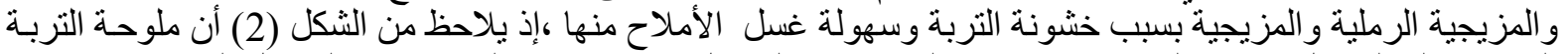

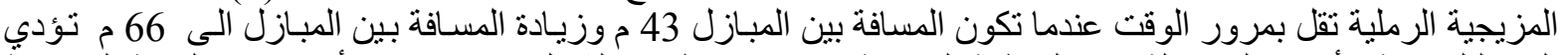

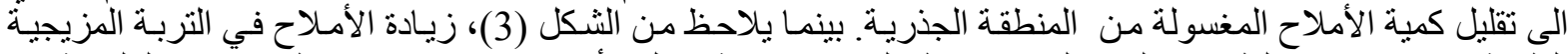

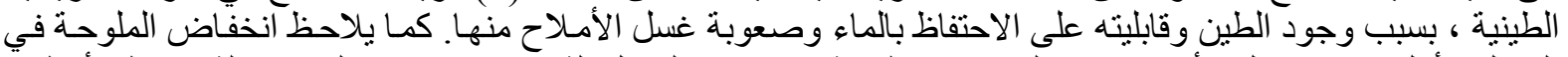

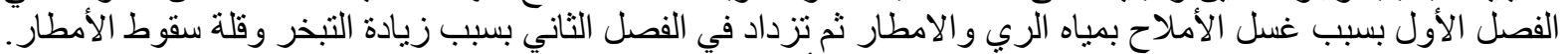

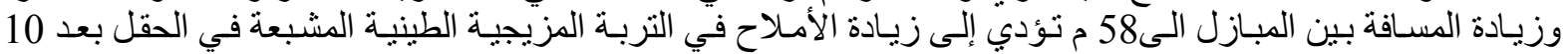

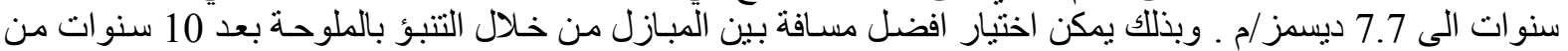
تطبيق الخطة الزر اعية المقترحة ومقارنتها مع الملوحة المسموح بهار بها في التربة.

الجدول (4) نتائج المسافة بين المبازل للترب المختلفة.

\begin{tabular}{|c|c|c|c|c|c|c|c|c|}
\hline \multirow{2}{*}{\multicolumn{2}{|c|}{ المسافة بين المبازل (م) الطينية }} & \multicolumn{2}{|c|}{ المزيجية } & \multicolumn{2}{|c|}{ المزيجية الرملية } & \multicolumn{2}{|c|}{ الرملية المزيجية } & \multirow{3}{*}{ المبزل } \\
\hline & & \multicolumn{2}{|c|}{ المسافة بين المبازل (م) } & \multicolumn{2}{|c|}{ المسافة بين المبازل (م) } & \multicolumn{2}{|c|}{ المسافة بين المبازل (م) } & \\
\hline الموازنة بعد & الفعلية & الموازنة بعد & الفعلية & الموازنة & الفعلية & الموازنة & الفعلية & \\
\hline 58 & 41 & 59 & 42 & 66 & 43 & 52 & 44 & 2.0 \\
\hline 61 & 43 & 65 & 45 & 67 & 46 & 54 & 47 & 2.1 \\
\hline 64 & 45 & 67 & 47 & 70 & 48 & 55 & 50 & 2.2 \\
\hline 66 & 48 & 69 & 49 & 72 & 50 & 58 & 51 & 2.3 \\
\hline 70 & 50 & 70 & 51 & 74 & 52 & 62 & 53 & 2.4 \\
\hline 72 & 51 & 73 & 53 & 79 & 54 & 64 & 55 & 2.5 \\
\hline
\end{tabular}

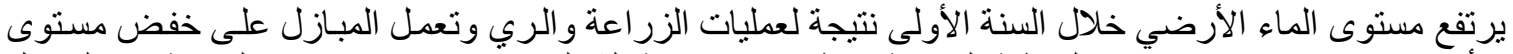

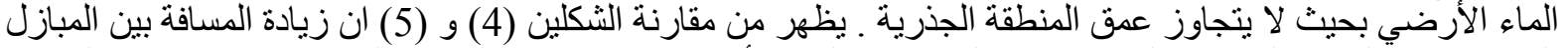

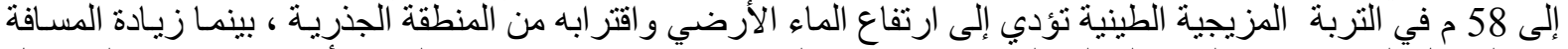

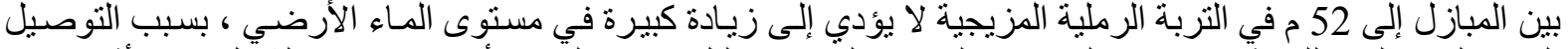

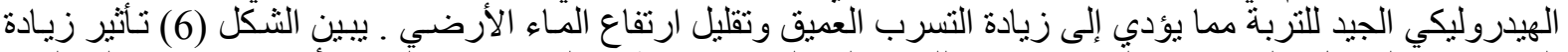

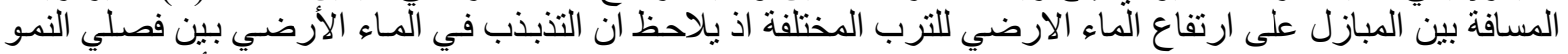

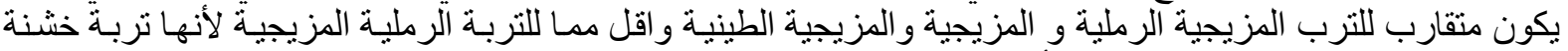

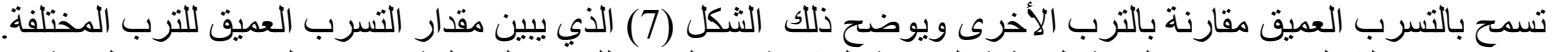

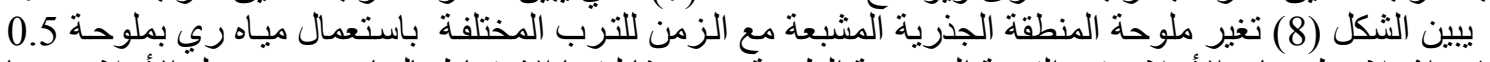

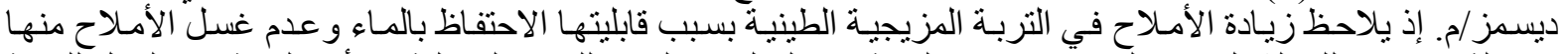

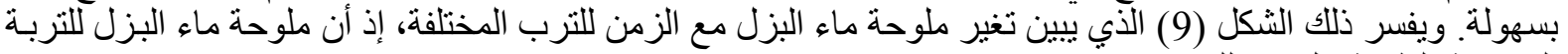

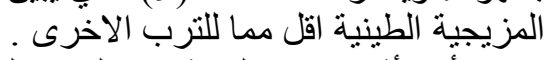

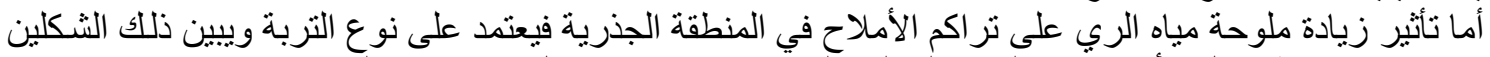

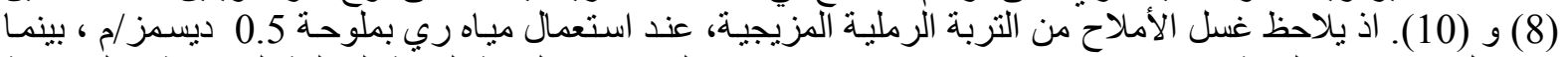

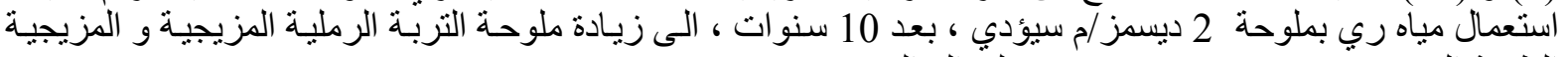
الطينية الى 14 ديسمز/م و 26 ديسمز /م على التو الي. 
غزال: تأثير المسافة بين المبازل على ارتفاع الماء الارضي وملوحة التربة

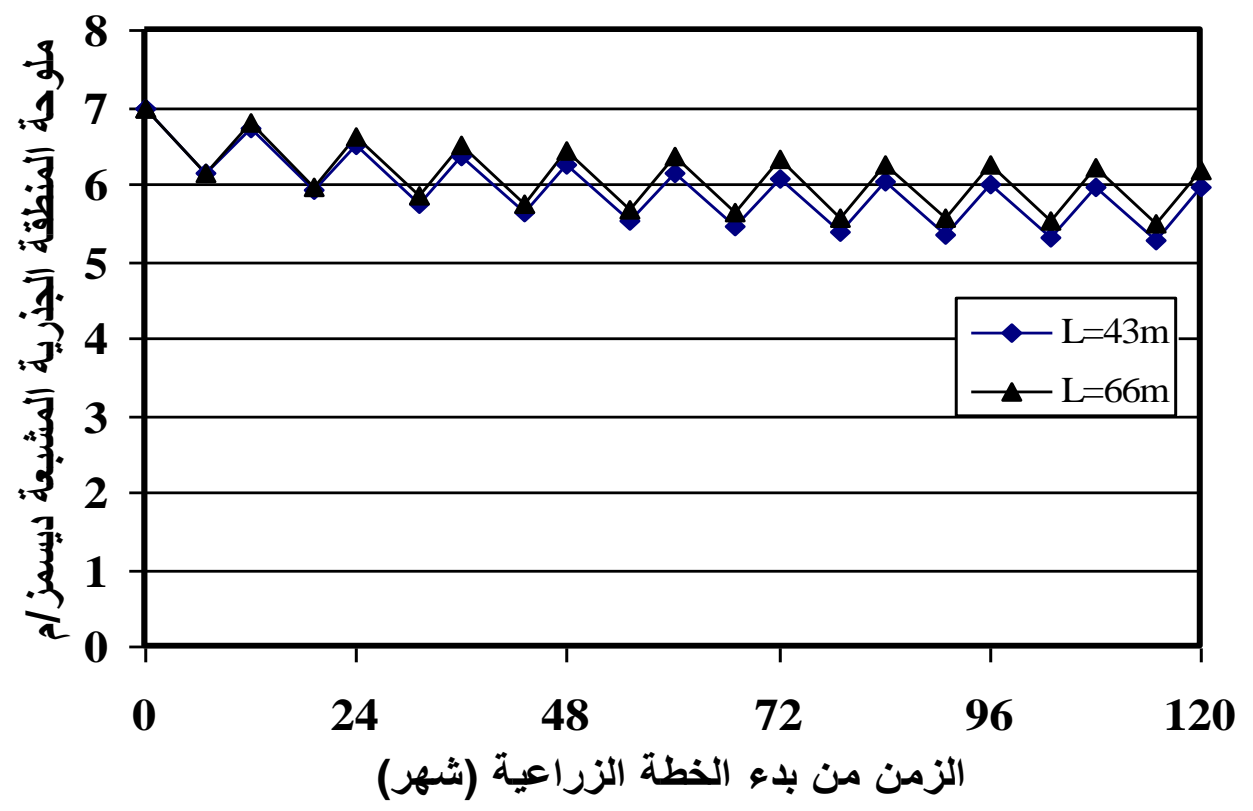

الثكل(2) تغير ملوحة المنطقة الجذرية المشبعة مع الزمن من بدء الخطة الزراعية لملوحة ماء ري 0.5

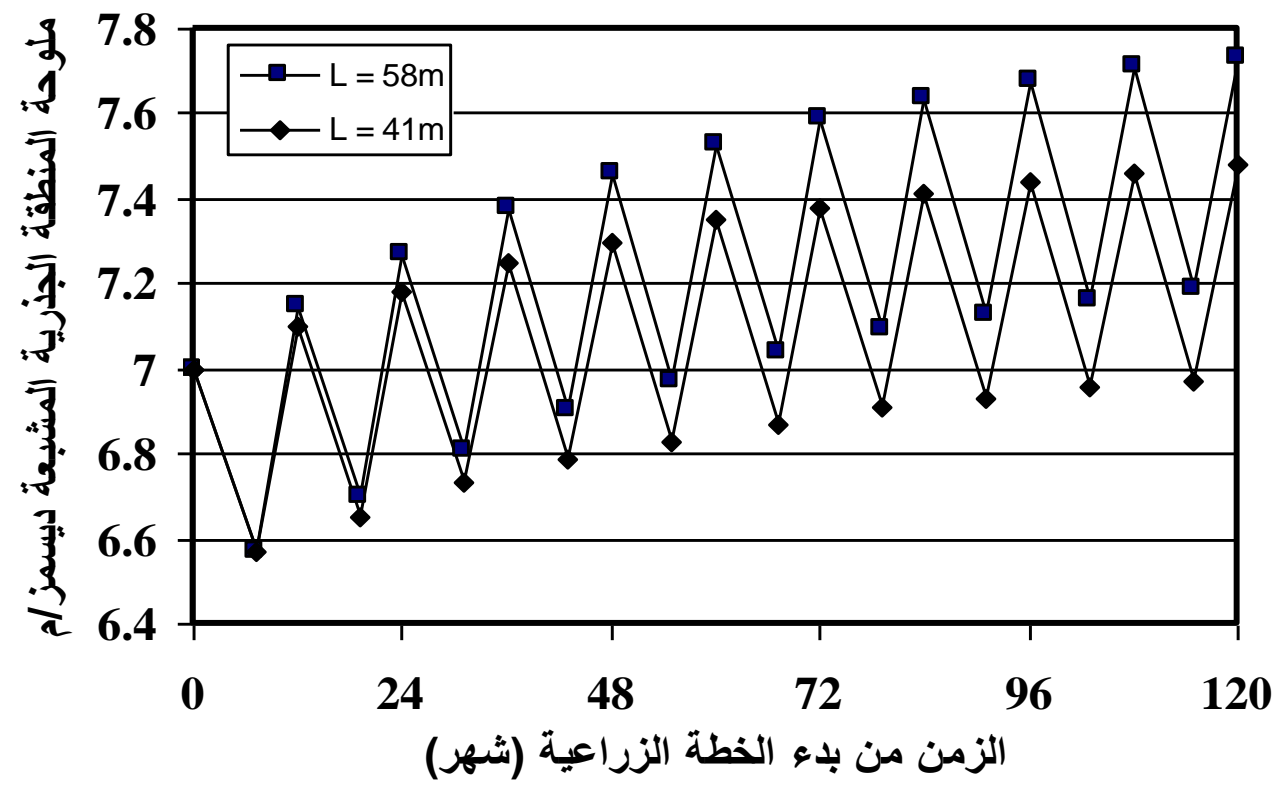

الثكل(3) تغير ملوحة المنطقة الجنرية المشبعة مع الزمن من بلدء الخطة الزراعية لملوحة ماء ري 0.5 ديسمز/م للتربة المزيجية الطئية الطينية. 


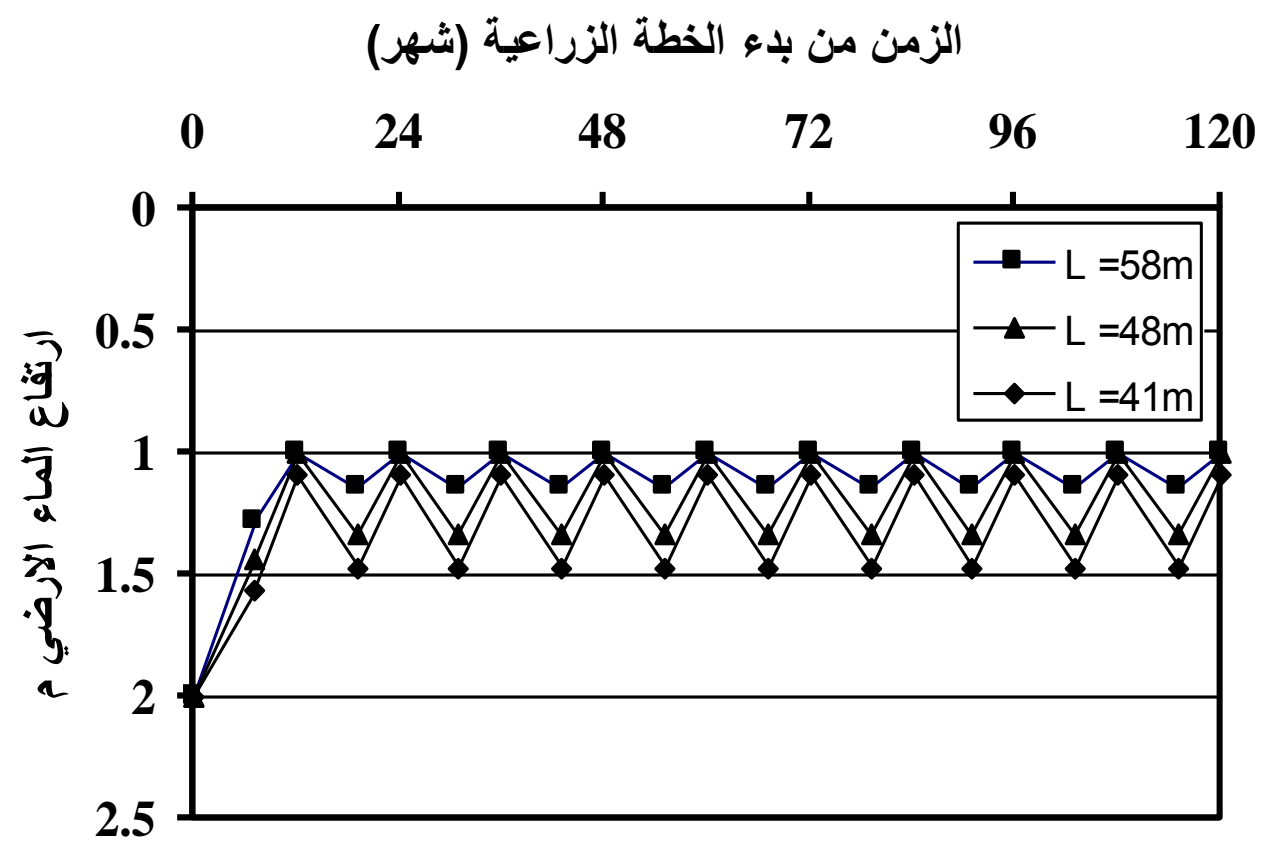

الثكل(4) تغير ارتفاع الماء الأرضي مع الزمن من بدء الخطة الزراعية للترب المزيجية الطينية.

الزمن من بدء الخطة الزراعية (شهر)

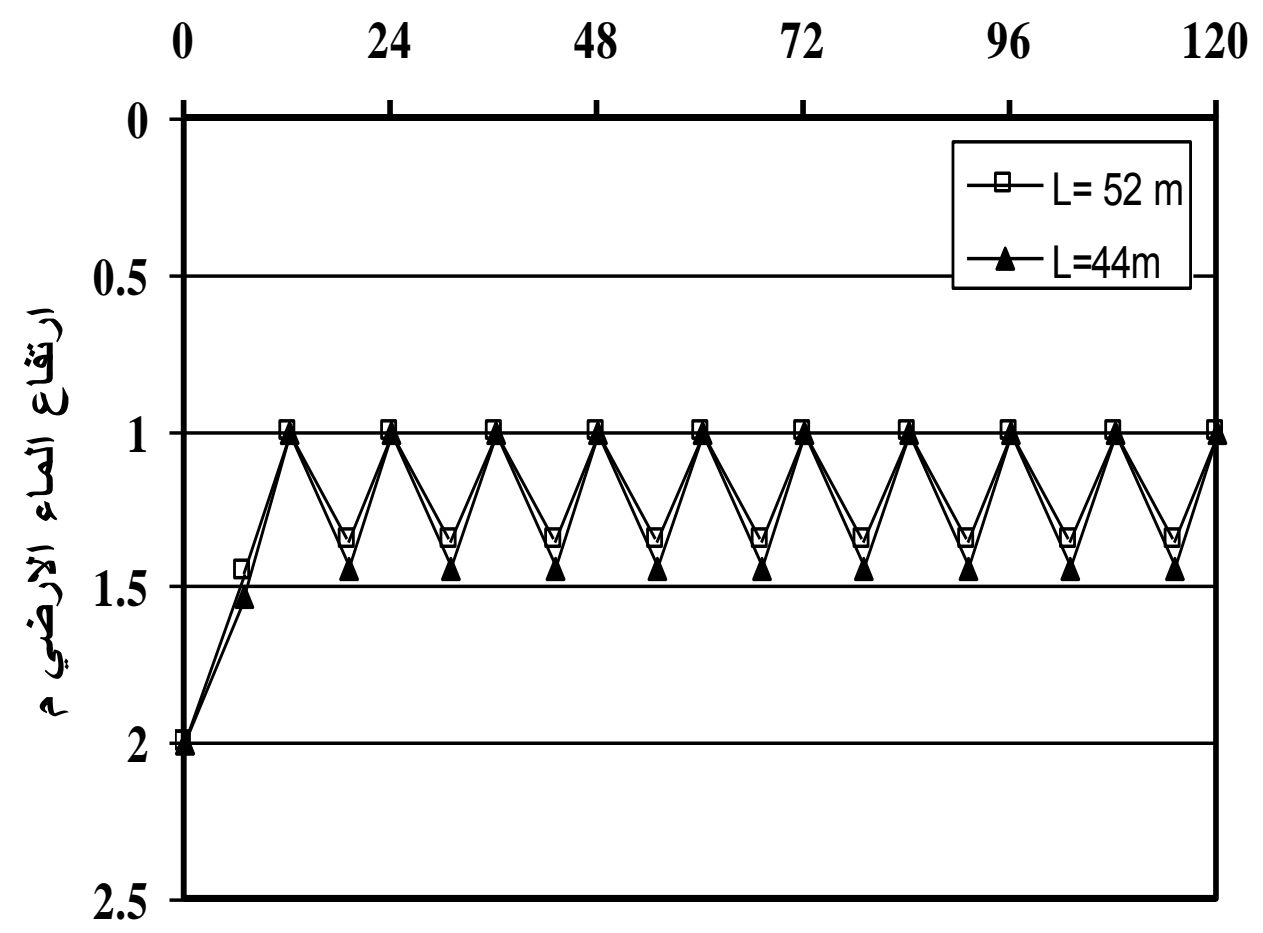

الثكل(5) تغير ارتفاع الماء الارضي مع الزمن من بدء الخطة الزراعية للتربة الرملية

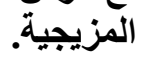




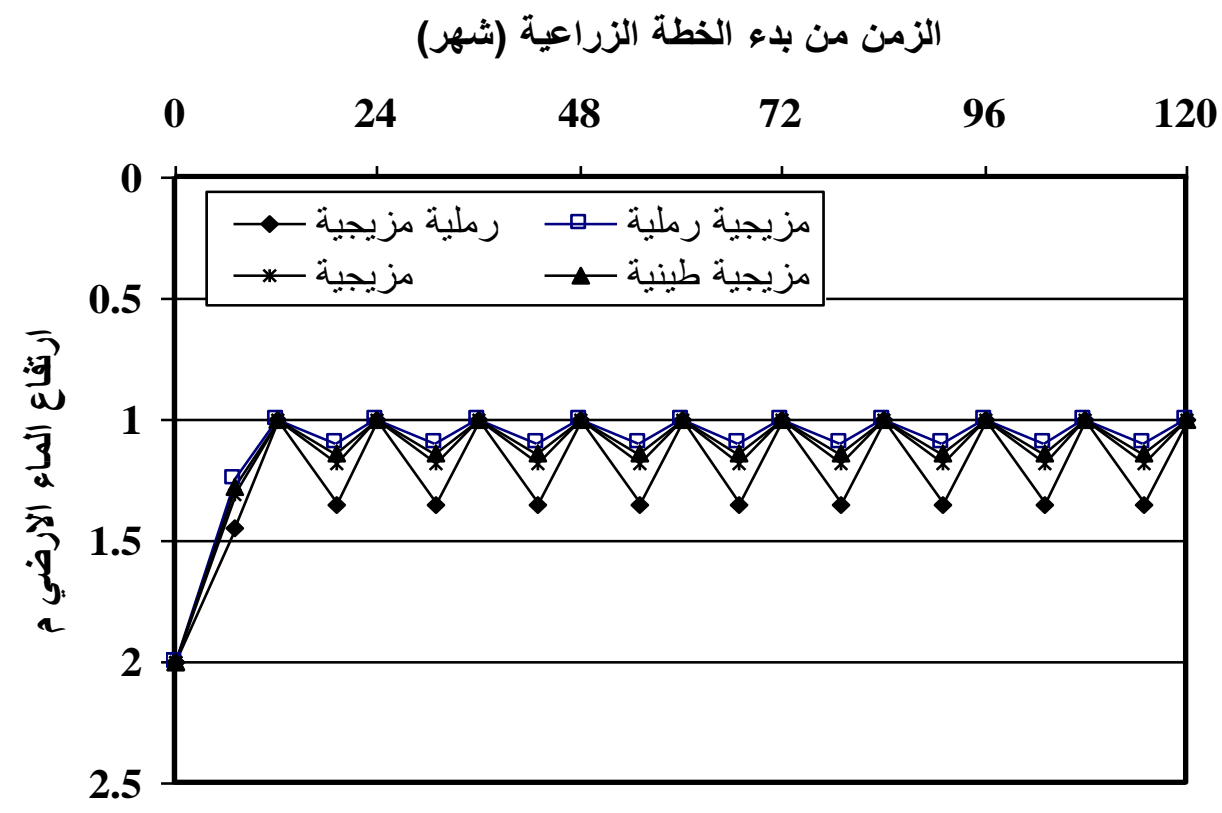

الثكل(6) تغير ارتفاع الماء الأرضي مع الزمن من بدء الخطة الزراعية للترب المختلفة.

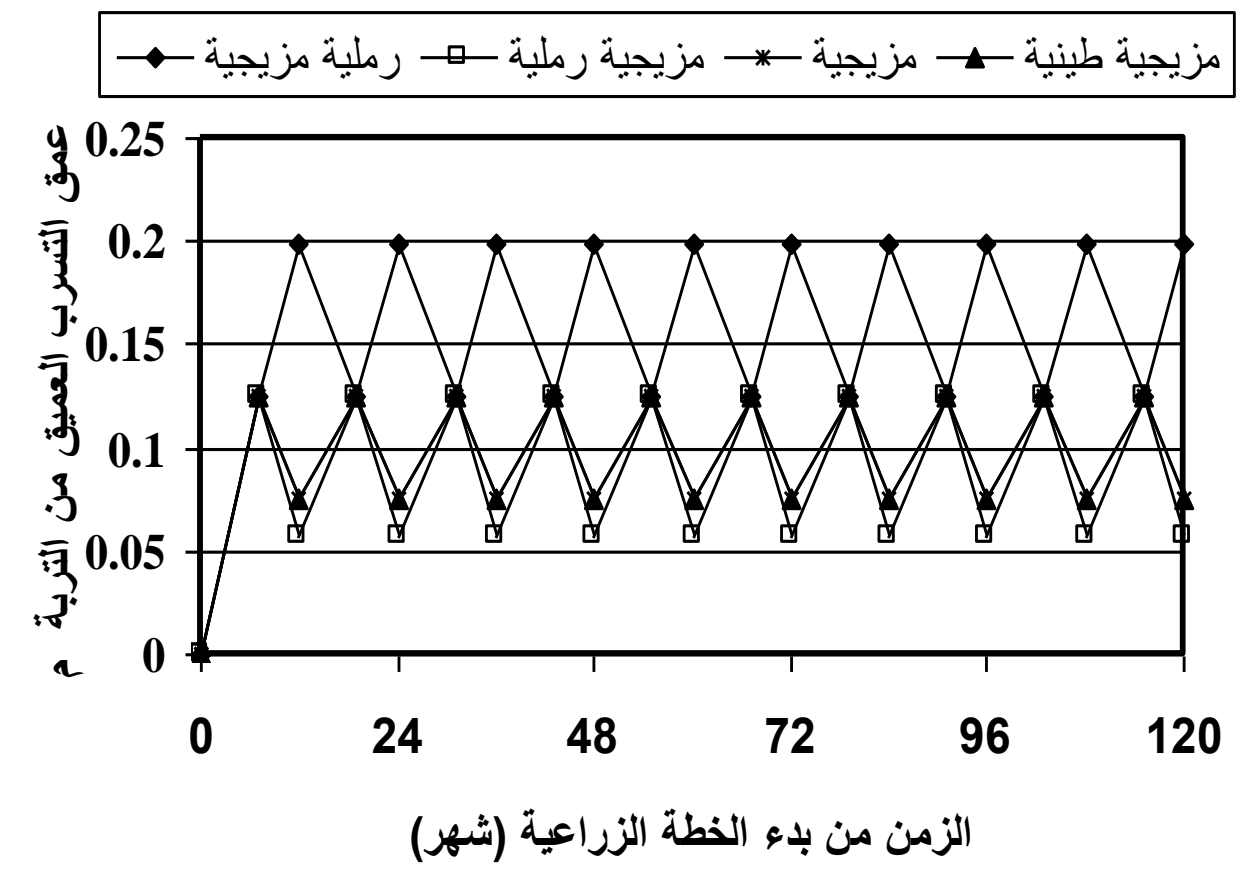

الثكل(7) عمق التسرب العميق من التربة مع الزمن من بدء الخطة الزراعية للترب المختلفة. 


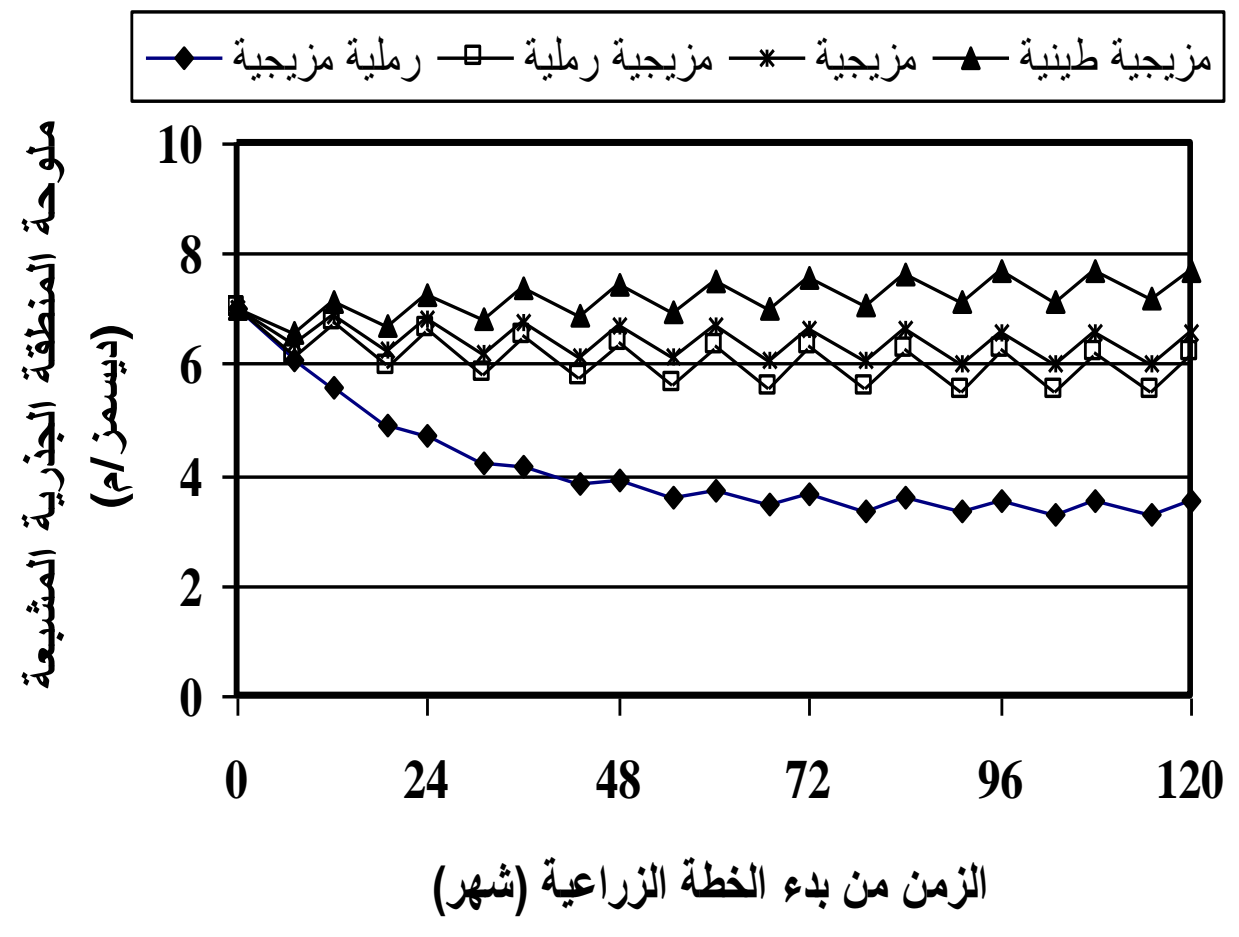

الثكل (8) تغير ملوحة المنطقة الجذرية المشبعة مي الزمن لملوحة ماء ري 0.5 ديسمزم للترب المختلفة.

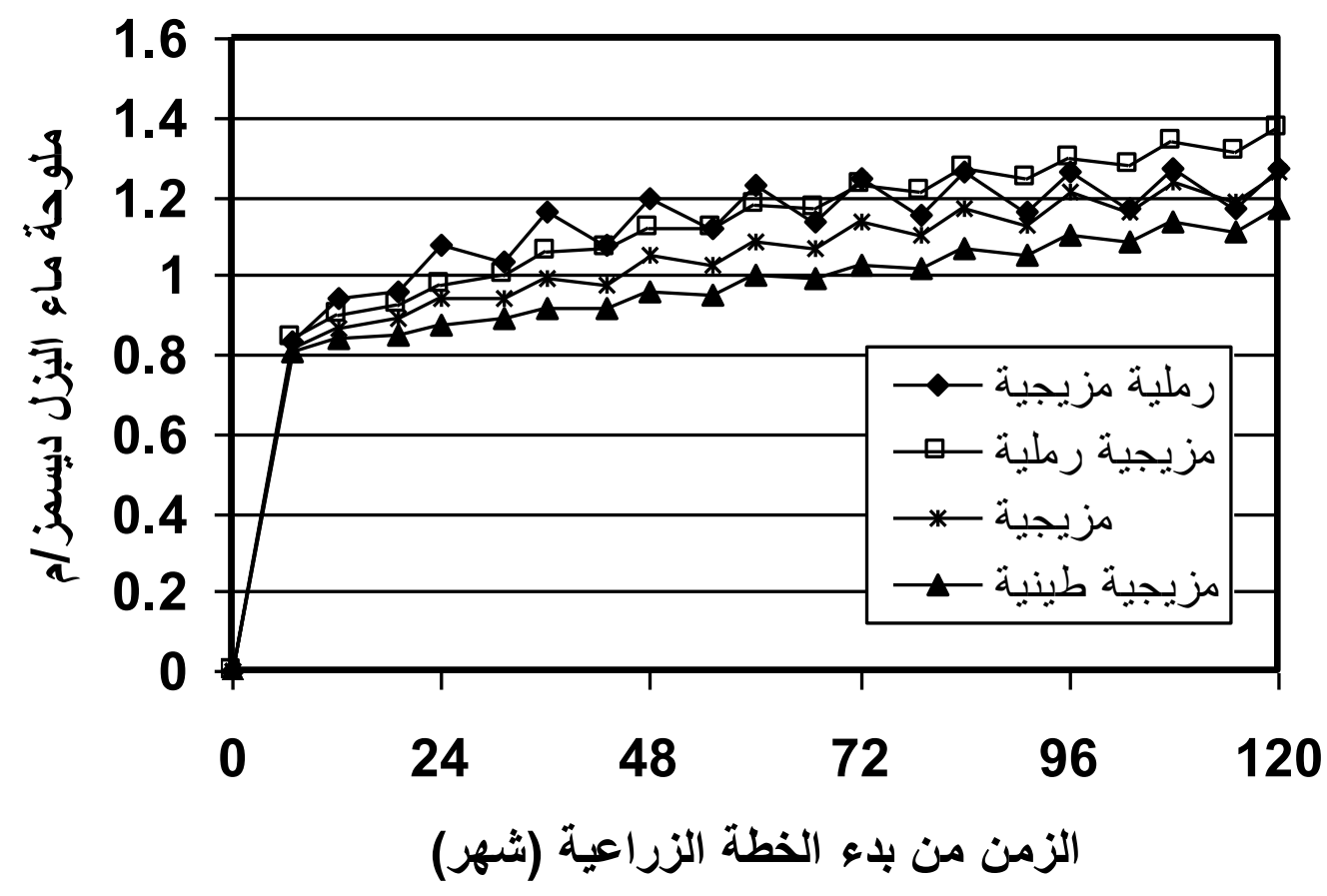

الثكل(9) تغير ملوحة ماء البزل مع الزمن من بدء الخطة الزراعية للترب المختلفة. 
غزال: تأثير المسافة بين المبازل على ارتفاع الماء الارضي وملوحة التربة

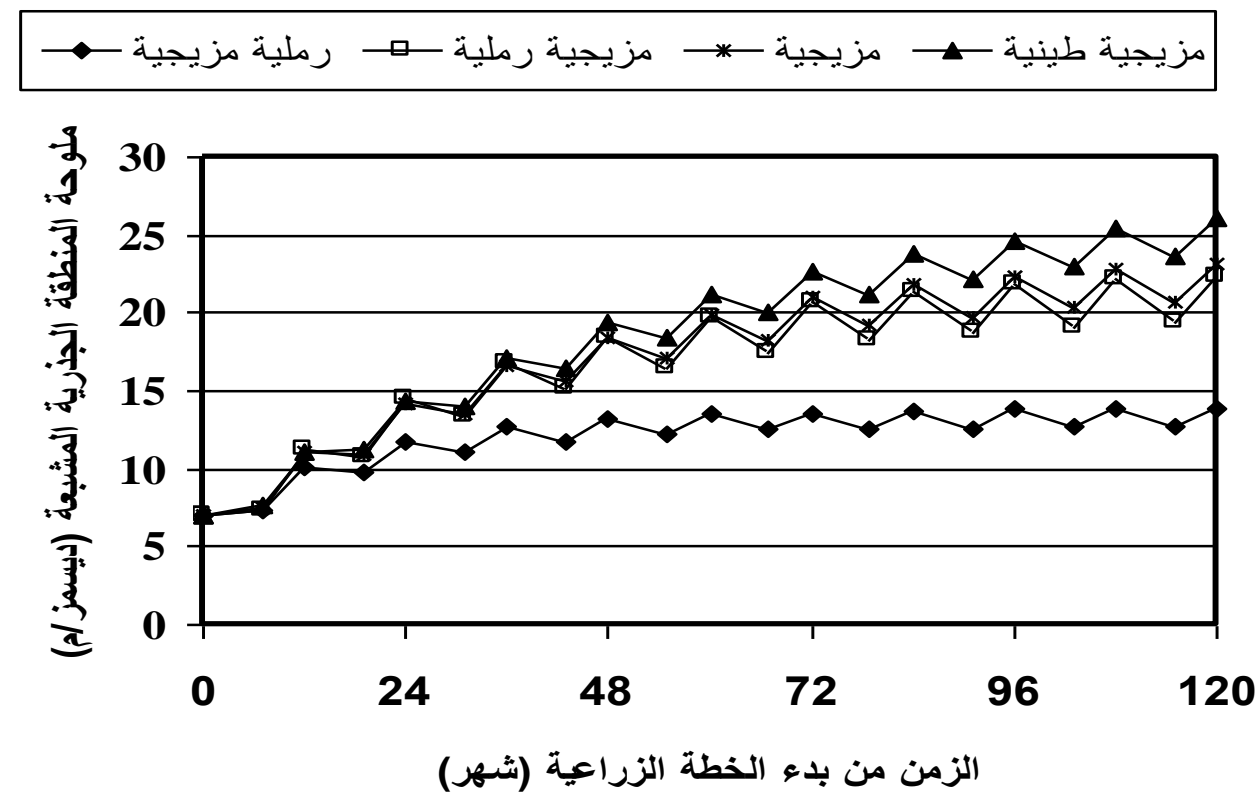

الثكل (10) تغير ملوحة المنطقة الجذرية المشبعة مع الزمن لملوحة ماء ري 2 ديسمز/م ل ل لترب المختلفة.

الجدول (5) التوزيع التكراري ( frequency distribution) لملوحة المنطقة الجذرية في السنة العاشرة للترب المختلفة ولملوحة ماء ري مختلفة.

\begin{tabular}{|c|c|c|c|c|c|c|c|c|}
\hline \multicolumn{9}{|c|}{ مياه ري 0.5 ديسمز/م } \\
\hline \multicolumn{2}{|c|}{ 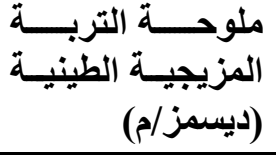 } & \multicolumn{2}{|c|}{ 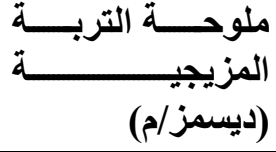 } & \multicolumn{2}{|c|}{ 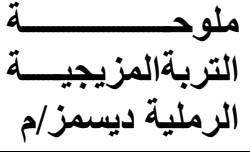 } & \multicolumn{2}{|c|}{ 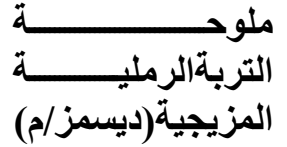 } & \multirow[t]{2}{*}{ التكراريــع } \\
\hline الثــــــــ & الأفصـــل & الثانصــــل & الأفصــل & الثانصــــل & الألصل & الثانصــــل & الأفصـــل & \\
\hline 9.46 & 8.74 & 8.0 & 7.32 & 7.53 & 6.68 & 4.3 & 4.01 & $\% 80$ \\
\hline 7.8 & 7.25 & 6.63 & 6.07 & 6.24 & 5.54 & 3.56 & 3.33 & $\% 60$ \\
\hline 6.67 & 6.2 & 5.67 & 5.19 & 5.34 & 4.74 & 3.05 & 2.84 & $\% 40$ \\
\hline 5.58 & 5.19 & 4.75 & 4.34 & 4.47 & 3.96 & 2.25 & 2.38 & $\% 20$ \\
\hline \multicolumn{9}{|c|}{ مياه ري 1 ديسمز/م } \\
\hline 17.1 & 15.6 & 14.9 & 13.5 & 14.3 & 12.5 & 8.5 & 7.89 & $\% 80$ \\
\hline 14.2 & 13.0 & 12.4 & 11.2 & 11.9 & 10.4 & 7.05 & 6.55 & $\% 60$ \\
\hline 12.1 & 11.1 & 10.6 & 9.57 & 10.1 & 8.89 & 6.03 & 5.6 & $\% 40$ \\
\hline 10.1 & 9.28 & 8.86 & 8.01 & 8.48 & 7.44 & 5.05 & 4.68 & $\% 20$ \\
\hline \multicolumn{9}{|c|}{ مياه ري 2 ديسمز/م } \\
\hline 31.7 & 28.6 & 28.2 & 25.1 & 27.2 & 23.6 & 16.8 & 15.4 & $\% 80$ \\
\hline 26.3 & 23.8 & 23.4 & 20.9 & 22.6 & 19.6 & 13.9 & 12.8 & $\% 60$ \\
\hline 22.5 & 20.3 & 20.0 & 17.8 & 19.3 & 16.7 & 11.9 & 10.9 & $\% 40$ \\
\hline 18.8 & 17.0 & 16.7 & 14.9 & 16.2 & 14.0 & 9.95 & 9.16 & $\% 20$ \\
\hline
\end{tabular}




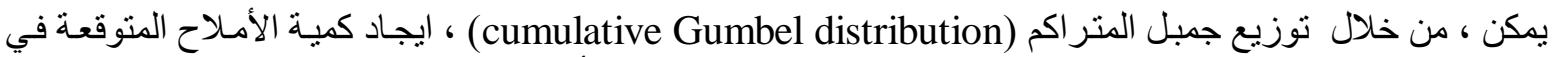

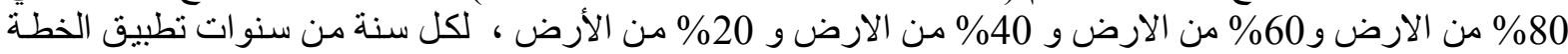

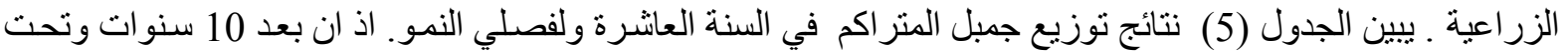

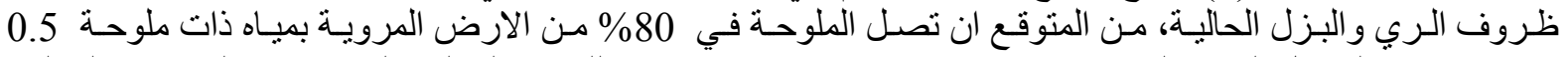

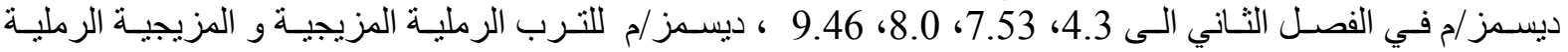

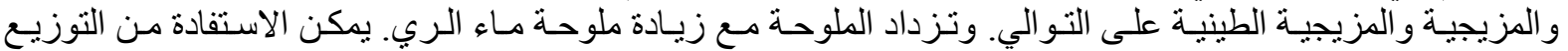

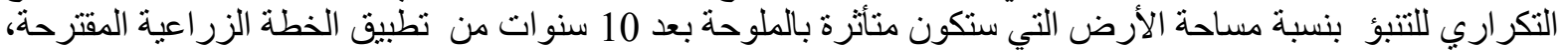

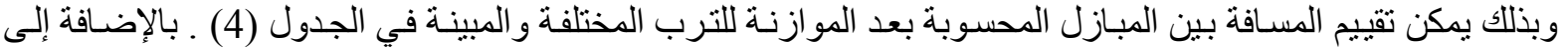
التنبؤ بتأثثر نوعية مياه الري على ملوحة التربة.

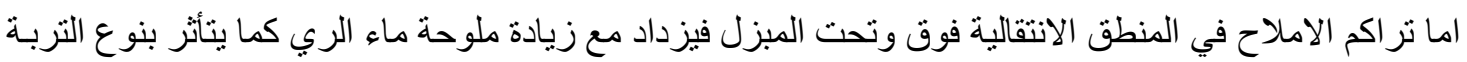

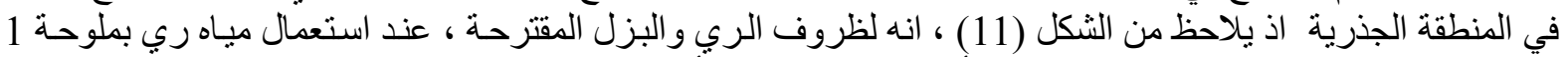

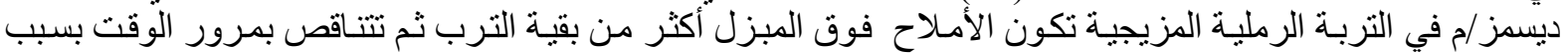

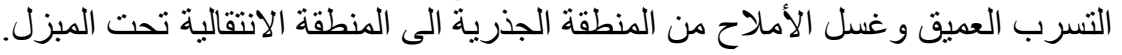

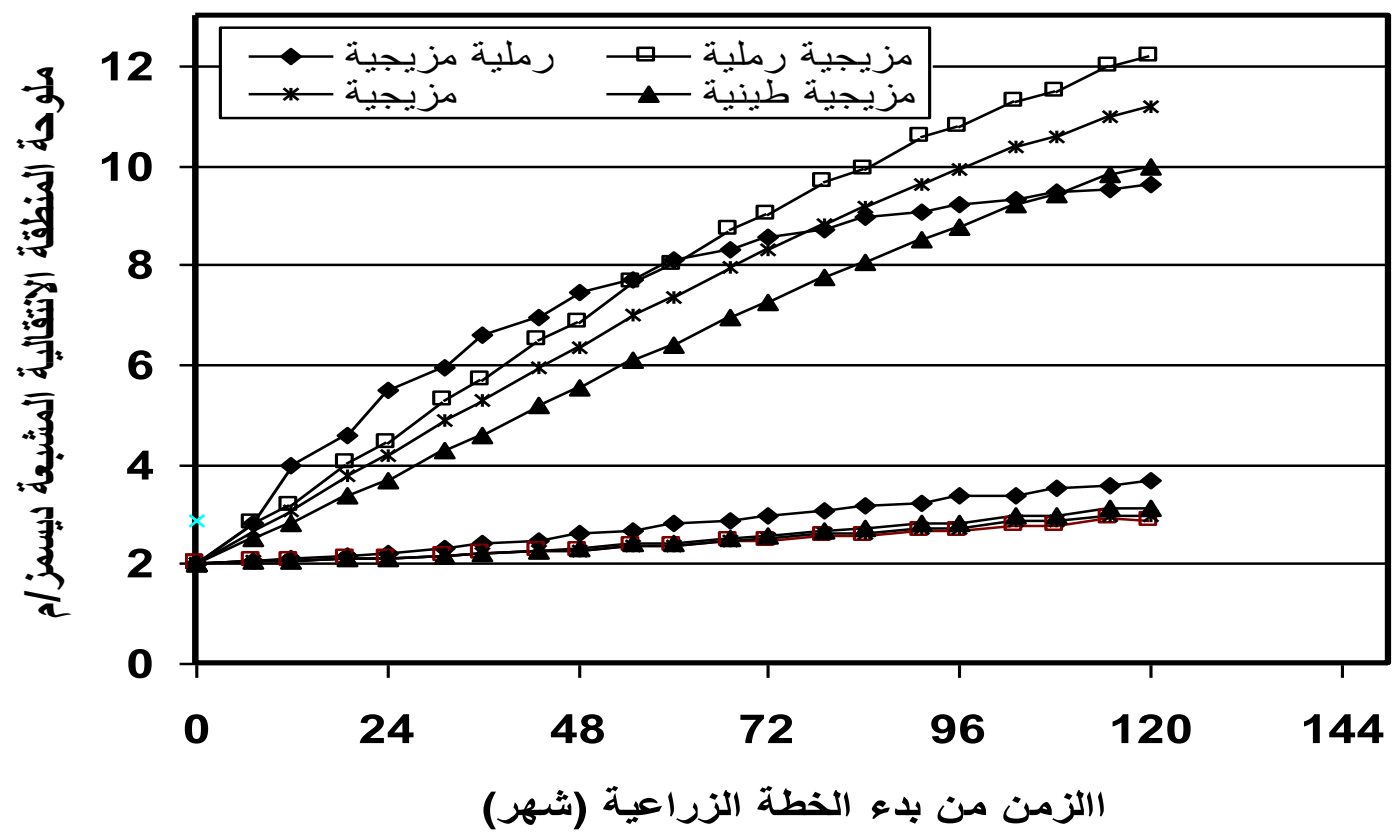

الثكل (11) تغير ملوحة المنطقة الانتقالية المشبعة مع الزمن من بلدء الخطة الزراعية للترب

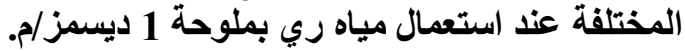

خاتمة

أنموذج SALTMOD أداة مفيدة للتنبؤ بملوحة المنطقة الجذريـة وعمق المـاء الأرضي ، وملوحسة مـاء البزل ، اعتمادا على الخطة الزر اعية المقترحة، بينت النتائج: 1- انخفاض الملوحة في الفصل الأول بسبب غسل الألماحلاح بمياه الري والإمطار ثم زيادتها في الفصل الثناني بسبب زيادة التبخر وقلة سقوط الأمطار.

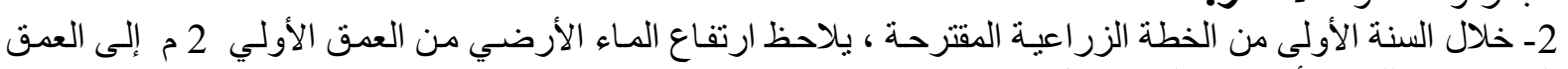

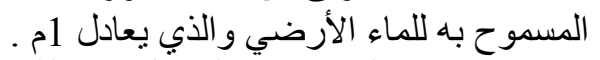

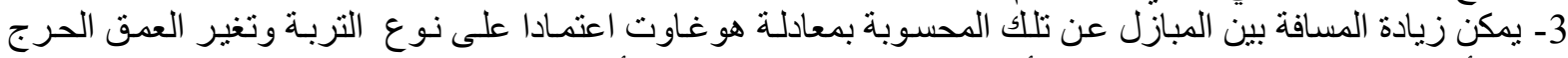

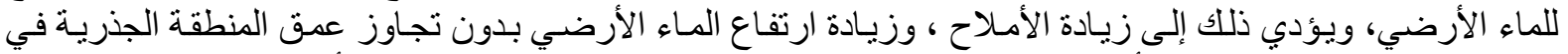

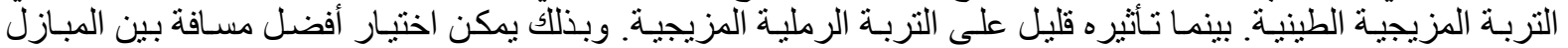
حسب الملوحة المسموح بها في التربة . 


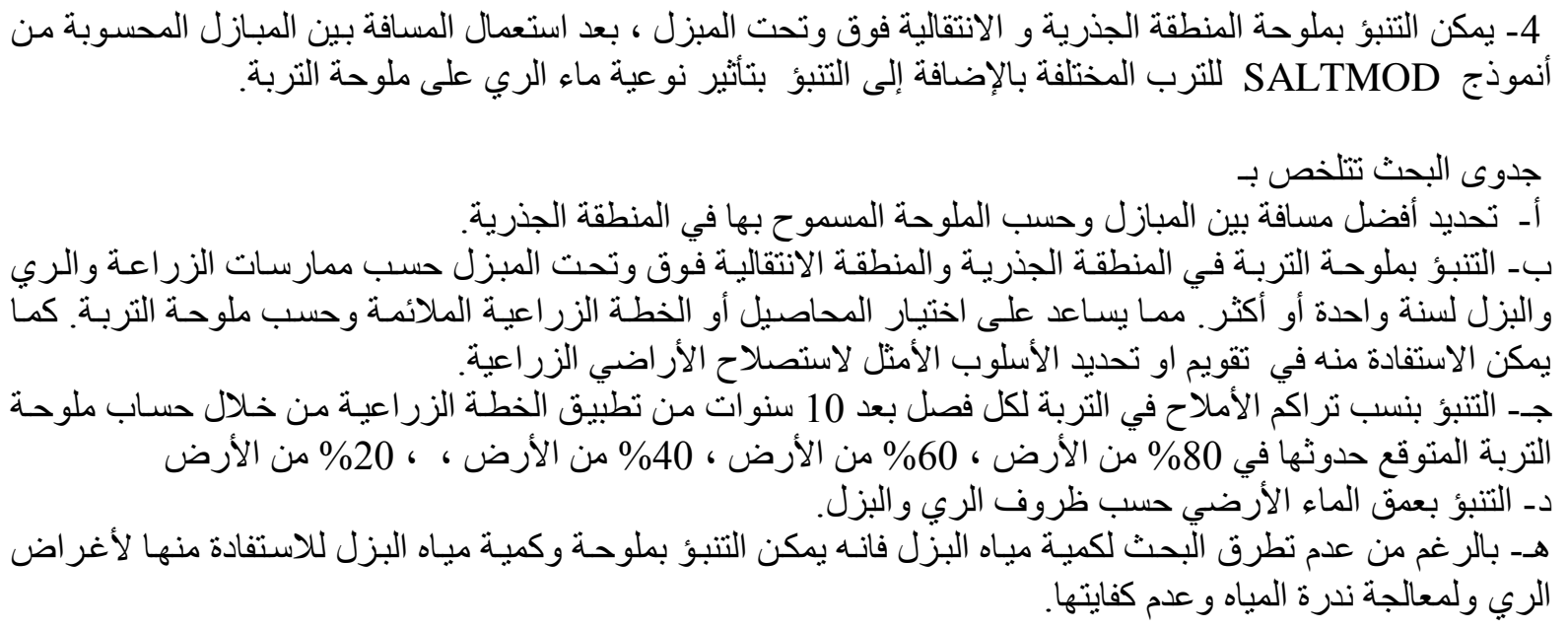

المصادر

1- Oosterbaan, R.J.( 2002). "SaltMod, Description of Principles, User Manual, and Examples of Application". ILRI Special Report. International Institute for Land Reclamation and Improvement, Wageningen, The Netherlands.96pp.

2- Vanegas Chacon, E.A .(1990)." Using SaltMod to predict desalinization in the Leziria Grande Polder, Portugal". Thesis. Wageningen Agricultural University, The Netherlands.

3- Oosterbaan R.J. \& Abu Senna M. (1990). "Using SaltMod to predict drainage and salinity control in the Nile delta". In: Annual Report 1989, International Institute for Land Reclamation and Improvement (ILRI), Wageningen, The Netherlands, p. 63-74.

4-Singh Man, Bhattacharya A.K., Singh A.K. \& Singh A.(2002)."Application of SALTMOD in coastal clay soil in india" . Irrigation and Drainage Systems 16: 213-231.

5- Srinivasulu, A.; Sujani Rao, Ch.; Lakshmi, G.V.; Satyanarayana, T.V.; Boonstra, J., (2004). "Model Studies on Salt and Water Balances at Konanki Pilot Area, Andhra Pradesh, India". Journal of Irrigation and Drainage Systems, Vol. 18, PP. 1-17.

6- Sharma, D.P., Singh, K, Rao, K.V. (2000). "Subsurface Drainage forRehabilitation of Waterlogged Saline Lands: Example of a Soil in Semiarid Climate".Vol.14, No. 4, pp. 373-386.

7- Madyaka, M., (2008). "Spatial Modelling and Prediction of Soil Salinization Using SALTMOD in a GIS Environment". M.Sc. Thesis, International Institute for GeoInformation Science and Earth Observation Enschede, the Netherlands.

8 - Bahçeci,I. , Nazmi, D., Tarı, A.F., Ağar, A. İ. and Bülent, S. B.( 2006). "Water and salt balance studies, using SaltMod, to improve subsurface drainage design in the Konya-Çumra Plain, Turkey" . Agricultural water management, Vol. 85,No. 3, Pp 261-271.

9- Bahçeci,I. , Suat Nacar, A. (2007)."Estimation of root zone salinity, using SaltMod, in the arid region of Turkey". Irrigation and Drainage Vol. 56 . No. 5 pp. $601-614$.

10- Bahçeci,I. , Cakir, R., Nacar, A. S. and Bahcec, P.N. (2008). "Estimating the Effect of Controlled Drainage on Soil Salinity and Irrigation Efficiency in the Harran Plain using SaltMod". Turkish Journal of Agriculture and ForestryVol.32 No. 2. pp.101-109. 11- تقييم اداء مشروع ري الجزيرة الثمالي(1990). شركة دجلة العامة للار اسات وتصاميم مشاريع الري، وزارة الري، الهيئة العامة لتشغيل مشاريع الرئري.

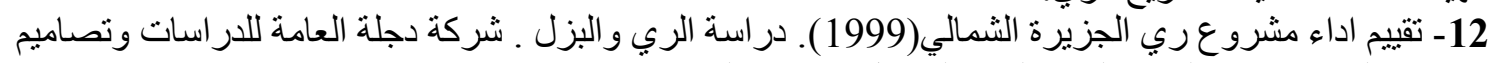

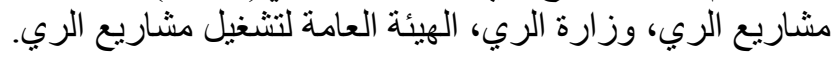
13 - Kessler, J., (1979). "Field Drainage Criteria. In: Drainage Principles and Applications", Publication 16, Vol. 2, International Institute for Reclamation and Improvement, Wageningen, The Netherlands 
14 - Israelsen, O. W. and Hansen, V. E., (1962). "Irrigation Principles and Practices". Wiley International Edition, $447 \mathrm{P}$.

15- Pencol, (1983). " Design Manual for Irrigation and Drainage". Republic of Iraq, Ministry of Irrigation, State Organization for Land Reclamation General Establishment for Design and Research, 530p

16- FAO/UNESCO.(1973)." Irrigation, Drainage and Salinity" . An international Source Book.

17- Allen, R. G., Pereira, L. S., Raes, D. and Smith, M., (1998). " Crop Evapotranspiration Guidelines for Computing Crop Water Requirements ". FAO Irrigation and Drainage paper No.56, Rome, Italy.

18- FAO, (1980). "Drainage Design Factors". FAO Irrigation and Drainage Paper No. 38, FAO, Rome .Italy.

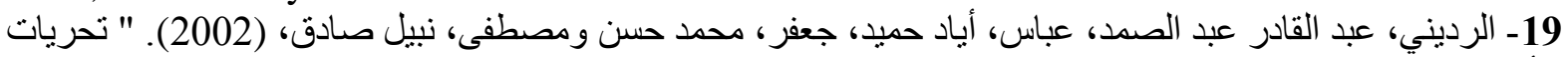

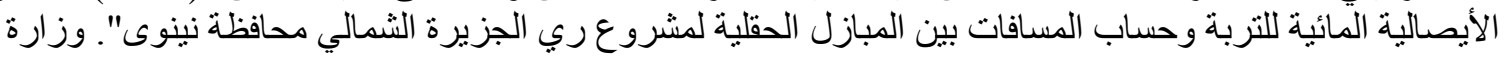

الري الثركة العامة لبحوث الموارد المائية والتربة قسم تحريات التربة، 20 صفحة.

تم اجراء البحث في كلية ألهندسة = جامعة ألموصل 